\title{
Vemurafenib-resistant BRAF selects alternative branch points different from its wild-type BRAF in intron 8 for RNA splicing
}

\author{
Masahiko Ajiro and Zhi-Ming Zheng*
}

\begin{abstract}
One mechanism of resistance of the melanoma-associated BRAF kinase to its small molecule inhibitor vemurafenib is by point mutations in its intron 8 resulting in exons 4-8 skipping. In this report, we carried out in vitro BRAF RNA splicing assays and lariat RT-PCR to map the intron 8 branch points in wild-type and BRAF mutants. We identify multiple branch points (BP) in intron 8 of both wild-type (wt) and vemurafenib-resistant BRAF RNA. In wt BRAF, BPs are located at $-29 \mathrm{~A},-28 \mathrm{~A}$ and $-26 \mathrm{~A}$, whereas in a vemurafenib-resistant BRAF splicing mutant, BPs map to $-22 \mathrm{~A},-18 \mathrm{~A}$ and $-15 \mathrm{~A}$, proximal to the intron $83^{\prime}$ splice site. This finding of a distal-to-proximal shift of the branch point sequence in BRAF splicing in response to point-mutations in intron 8 provides insight into the regulation of BRAF alternative splicing upon vemurafenib resistance.
\end{abstract}

Keywords: BRAF, RNA splicing, Branch point mapping, Lariat RT-PCR, Vemurafenib-resistance

\section{Background}

BRAF proto-oncogene encodes a serine/threonine kinase regulator of the MAP kinase pathway, and activating BRAF mutations are found in $40-60 \%$ of melanoma, with $90 \%$ of them containing the V600E mutation [1, 2]. Vemurafenib, a potent inhibitor of (V600E) BRAF in melanoma cells, is currently in clinical use [3-5]. However, patients treated with vemurafenib develop resistance by activation of alternative signaling pathways [6-9] or by inducing alternative splicing of BRAF to exclude the RAS-binding domain encoded by exons $3-5$ [10]. The vemurafenib-resistant melanoma cell line C3 SKMEL239 produces BRAF exon $3^{\wedge} 9$ splicing and contains two intronic point-mutations at positions -435 (C-to-A) and -51 (C-to-G) from the BRAF intron $83^{\prime}$ splice site. In a minigene system the -51 mutation, located in the computationally predicted branch point (BP), was found to be sufficient to recapitulate BRAF exon $3^{\wedge} 9$ splicing $[10,11]$.

\footnotetext{
*Correspondence: zhengt@exchange.nih.gov

Tumor Virus RNA Biology Section, Gene Regulation and Chromosome

Biology Laboratory, National Cancer Institute, National Institutes

of Health, Frederick, MD 21702, USA
}

Each intron of eukaryotic primary RNA transcripts (pre-mRNAs) has a $5^{\prime}$ splice site with a GU dinucleotide and a $3^{\prime}$ splice site with an AG dinucleotide. The $3^{\prime}$ splice site also contains a BP in a 7-nt or 5 -nt branch point sequence (BPS) and a run of 15-40 pyrimidines (usually Us), called polypyrimidine tract (PPT), between the BPS and the $3^{\prime}$ end AG dinucleotide. Defining the exon-intron boundary in pre-mRNA splicing is the first step in the accurate recognition of an intron $5^{\prime}$ splice site by U1 snRNA, of BPS by U2 snRNA, and of a $3^{\prime}$ splice site by U2AF (U2 auxiliary factors) modulated by many cellular splicing factors [12-14]. These recognition steps are followed by two transesterification reactions during spliceosome assembly. In this two-step biochemical reaction, an $\mathrm{OH}$ group of the BP adenosine within the BPS performs a nucleophilic attack on a phosphodiester bond of the intron- $5^{\prime}$ exon junction, resulting in the first step in the $5^{\prime}$ exon being cleaved off and forming a lariat intermediate by a branching reaction of the intron $5^{\prime}$ end $\mathrm{G}$ to the BP adenosine via a $5^{\prime}$-to- $2^{\prime}$ phosphodiester link. The second step is to cleave the intron from the lariat intermediate by another nucleophilic attack of the $\mathrm{OH}$ group from the cleaved $5^{\prime}$ exon on a phosphodiester bond of the intron- $3^{\prime}$ exon junction and join the cleaved $5^{\prime}$ exon to 
the cleaved $3^{\prime}$ exon. Thus, if an intron $5^{\prime}$ and $3^{\prime}$ splice sites are of consensus sequence, they sequentially bind three different splicing factors in order to assemble the spliceosome. However, the splice sites in higher eukaryotes are usually not well conserved and binding of splicing factors to pre-mRNAs with non-consensus sequence is often inefficient. In addition, pre-mRNA splicing is subject to regulation by other intronic or exonic cis-elements, intronic splicing enhancers (ISE) or silencers (ISS) and exonic splicing enhancer (ESE) or silencer (ESS), often located at a distance. The combination of the strength of the various cis-regulatory elements and the local availability of splicing factors determines alternative splicing outcome $[13,14]$.

In this report, we experimentally mapped the BPS in BRAF intron 8 that controls the constitutive RNA splicing of wild-type $(\mathrm{wt}) \mathrm{BRAF}$ exon $8^{\wedge} 9$ and discovered an alternative BPS in the intron 8 of a vemurafenb-resistant mutant (mt) BRAF pre-mRNA.

\section{Result and discussion}

\section{BRAF intron 3 and intron 8 are suboptimal}

Both annotated BRAF intron 3 and intron 8 are large, with a size of $\sim 25.6 \mathrm{~kb}$ for the intron 3 and $6.7 \mathrm{~kb}$ for intron 8 . To understand what might contribute to the observed alternative exon $3^{\wedge} 9$ splicing of vemurafenibresistant BRAF RNA, we analyzed sequence structures of the $5^{\prime}$ and $3^{\prime}$ splice sites in BRAF introns 3 and 8 and also the $5^{\prime}$ splice site of BRAF intron 9 considering that exon definition may play an important role in defining an upstream $3^{\prime}$ splice site $[13,15,16]$. Recognition of an intron $5^{\prime}$ splice site by U1 snRNA requires the $5^{\prime}$-terminal 11 nts of the U1 snRNA to base-pair directly with the $5^{\prime}$ splice site [17]. We found that all three analyzed $5^{\prime}$ splice sites have consensus sequence GURAGU $[18,19]$, but only intron 3 and intron $95^{\prime}$ splice sites can base-pair fully to the six core nucleotides of the U1 snRNA $5^{\prime}$ end, whereas the intron $85^{\prime}$ splice site is missing a nucleotide at position -1 upstream of the 5 splice site (Fig. 1a). The inability of the U1 snRNA $5^{\prime}$ core nucleotide to fully base-pair with the $5^{\prime}$ splice site affects U1 snRNA binding and decreases splice site strength [20-22].

In general, a consensus $3^{\prime}$ splice site is composed of three critical elements: BPS, PPT (usually with a stretch of $U$ residues), and an AG dinucleotide at the $3^{\prime}$ end of the intron. Mammalian consensus BPSs are YNYURAC [23, 24] or YUNAN, [25-27] with $90 \%$ of BPSs occurring within 19-37 (median 25) nucleotides upstream of the $3^{\prime}$ AG dinucleotides and $78 \%$ of the BP nucleotides within a BPS being an adenosine [27]. Analysis of the intron 3 and intron $83^{\prime}$ splice sites using Human Splice Finder (http:// www.umd.be/HSF/) [28] revealed that both introns bear a non-consensus 7-nt BPS within the distance range in intron 3, but further upstream (46 nts) in intron 8 . The intron $83^{\prime}$ splice site is also predicted to have multiple non-consensus 5-nt BPSs within the distance range to its $3^{\prime}$ AG dinucleotide (Fig. 1b). Moreover, both introns have a weak PPT interspersed by purines with runs of uridines no longer than three. Altogether, the weak nature of these $3^{\prime}$ splice sites would subject them to regulation by RNA cis-elements or trans-acting factors.

\section{Reconstitution of wt exon $8 \wedge 9$ and $m t$ exon $3 \wedge 9$ splicing of BRAF in vitro}

When compared to the melanoma SKMEL-239 cells which are sensitive to vemurafenib treatment, the vemurafenib-resistant melanoma C3 SKMEL-239 cells harbor both -435 C-to-A and -51 C-to-G mutations within the BRAF intron 8 and exhibit activation of BRAF exon $3^{\wedge} 9$ splicing, leading to reduction of the constitutive BRAF exon $8^{\wedge} 9$ splicing of BRAF (Fig. 2a, b). The -51 mutation has been shown to be sufficient to induce exon $3^{\wedge} 9$ splicing in a BRAF minigene system [11]. To map the BPS directing exon $8^{\wedge} 9$ and exon $3^{\wedge} 9$ splicing of BRAF in vitro, and because the annotated BRAF intron 3 $(\sim 25.6 \mathrm{~kb})$ and intron $8(6.7 \mathrm{~kb})$ are extremely large, we constructed a wt BRAF DNA template with a truncated intron 8 from SKMEL-239 cells and a mt BRAF DNA template with a chimeric intron 3 and intron 9 from $\mathrm{C} 3$ SKMEL-239 cells for generation of pre-mRNAs under a T7 promoter. Thus, the wt BRAF pre-mRNA transcribed in vitro had a truncated intron 8 from the middle of the intron and the mt BRAF pre-mRNA had a chimeric intron of which the intron $35^{\prime}$ splice site (64 nts) was fused with the intron $83^{\prime}$ splice site (440 nts) including the point mutations in the intron (Fig. 3a). The $3^{\prime}$ end of each BRAF pre-mRNA used in this assay also contained a native $5^{\prime}$ splice site (a U1-binding site) from intron 9 (Fig. 3a, pre-mRNAs 1 and 3, also Fig. 1a) or a consensus U1-binding site (Fig. 3a, pre-mRNAs 2 and 4) to promote RNA splicing efficiency [29]. In vitro RNA splicing was conducted in the presence of HeLa nuclear extract [30, 31]. This in vitro RNA splicing assay revealed that both wt and mt BRAF pre-mRNAs spliced equally efficiently in a $2 \mathrm{~h}$ reaction, with the expected sizes of splicing products (Fig. 3b) and accumulation of splicing lariats and lariat-intermediates from all four pre-mRNAs (Fig. 3b, top two bands). There was no difference in splicing efficiency among the BRAF pre-mRNAs with a consensus U1 binding site or a native $\mathrm{U} 1$ binding site from the intron 9 attached to the RNA $3^{\prime}$ end. Interestingly, we noticed that the lariats and lariat-intermediates derived from $\mathrm{mt}$ BRAF exon $3^{\wedge} 9$ splicing were running slower than that of wt BRAF exon $8^{\wedge} 9$ splicing in a $6 \%$ denaturing PAGE gel (Fig. 3b). Although the intron of mt BRAF pre-mRNAs is 13 nts longer than that of the wt BRAF pre-mRNAs, 
a
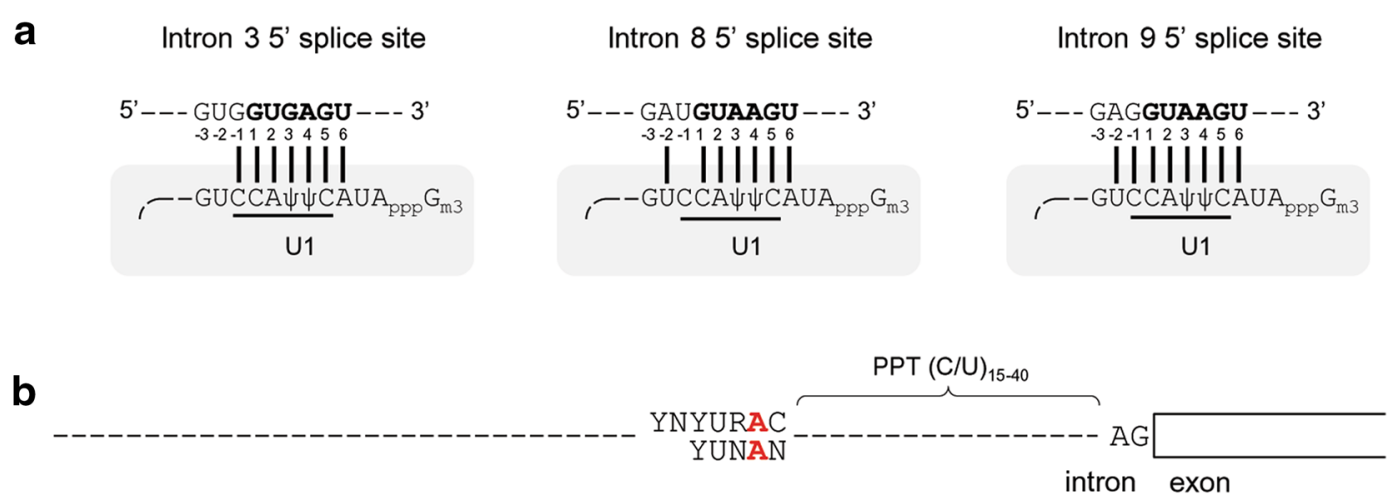

CV: 80.9

Bulged A: -24
Intron 9 5' splice site

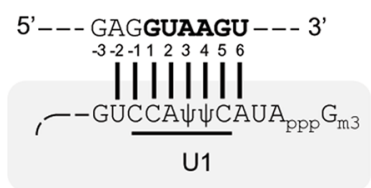

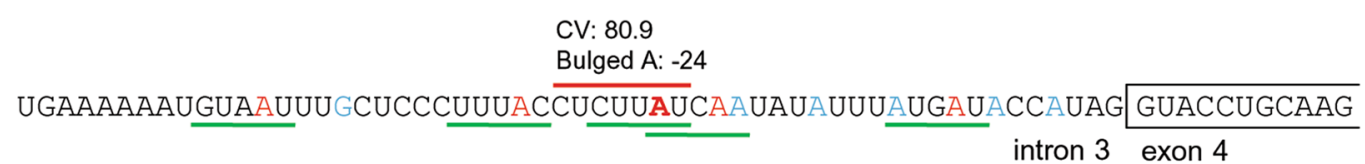

Red $=$ predicted 7-nt BPS

Blue $=$ predicted 5 -nt BPS

Fig. 1 Suboptimal features of the BRAF intron 3 and intron 8. a The sequences of indicated $5^{\prime}$ splice sites in base-pairing with the $5^{\prime}$ end of U1 snRNA. The lines below the U1 sequences indicate six most important U1 $5^{\prime}$ end nucleotides (core) for base-pairing with each $5^{\prime}$ splice site during $5^{\prime}$ splice site recognition. The intron $5^{\prime}$ end sequences are bolded with the intron 5 end $\mathrm{G}$ as position 1 and the exon $3^{\prime}$ end nucleotide immediately upstream of the intron $5^{\prime}$ end $\mathrm{G}$ as position -1. b The sequences of intron 3 and intron $83^{\prime}$ splice sites with predicted 7-nt (red lines) and 5-nt BPS (green lines). The mammalian consensus 7-nt BPS sequence YNYURAC [23, 24] or 5-nt YUNAN [25-27] are shown for comparison. Red color A in the predicted 7-nt BPS and in the predicted 5-nt BPS indicates the putative BP adenosine A. Conservation value (CV) for each predicted 7-nt BPS is calculated by using Human Splice Finder (http://www.umd.be/HSF/), with indicated distance of the bulged A from the downstream $3^{\prime}$ splice site. Purines in the putative PPT are labeled in light blue or red

the observed slowly migrating lariats and lariat-intermediates derived from mt BRAF pre-mRNAs suggested that a larger loop in the mt lariats than the wt lariats was formed when a $5^{\prime}-2^{\prime}$ phosphodiester branching reaction during mt RNA splicing occurred between the intron $5^{\prime}$ splice site GU and a BP nucleotide. These data indicate that the mt RNA might utilize a BPS closer to the intron $3^{\prime}$ splice site than the wt RNA.

\section{Identification of distinct sets of alternative BPs for wt and $m t$ BRAF splicing by lariat RT-PCR}

Given the successful reconstitution of wt and mt BRAF splicing in vitro, we then performed lariat RT-PCR on the lariats and lariat-intermediates derived from BRAF pre-mRNAs 1 and 3. In the lariat RT-PCR, SuperScript
II induces a nucleotide substitution at the BP by reading through the BP $5^{\prime}$-to- $2^{\prime}$ phosphodiester bond present in the lariats or lariat-intermediates during reverse transcription, thereby converting the lariat circle into linear cDNA that can be amplified by PCR. Thus, lariat RT-PCR specifies the branched nucleotide from a BPS upstream of the $3^{\prime}$ splice site AG dinucleotide and has been widely used for branch point mapping (Fig. 4a) [31-33]. Lariat RT-PCR products from the wt and mt BRAF RNA splicing (Fig. 3b) were gel-extracted (Fig. 4b) and analyzed by TA-cloning and sequencing (Fig. 4c). After screening of 23 bacterial colonies from each lariat RT-PCR product, we found that eight colonies had an insertion of the wt lariat products and others displayed no insertion. Three adenosines, $-29 \mathrm{~A},-28 \mathrm{~A}$ and $-26 \mathrm{~A}$ from the intron $83^{\prime}$ 


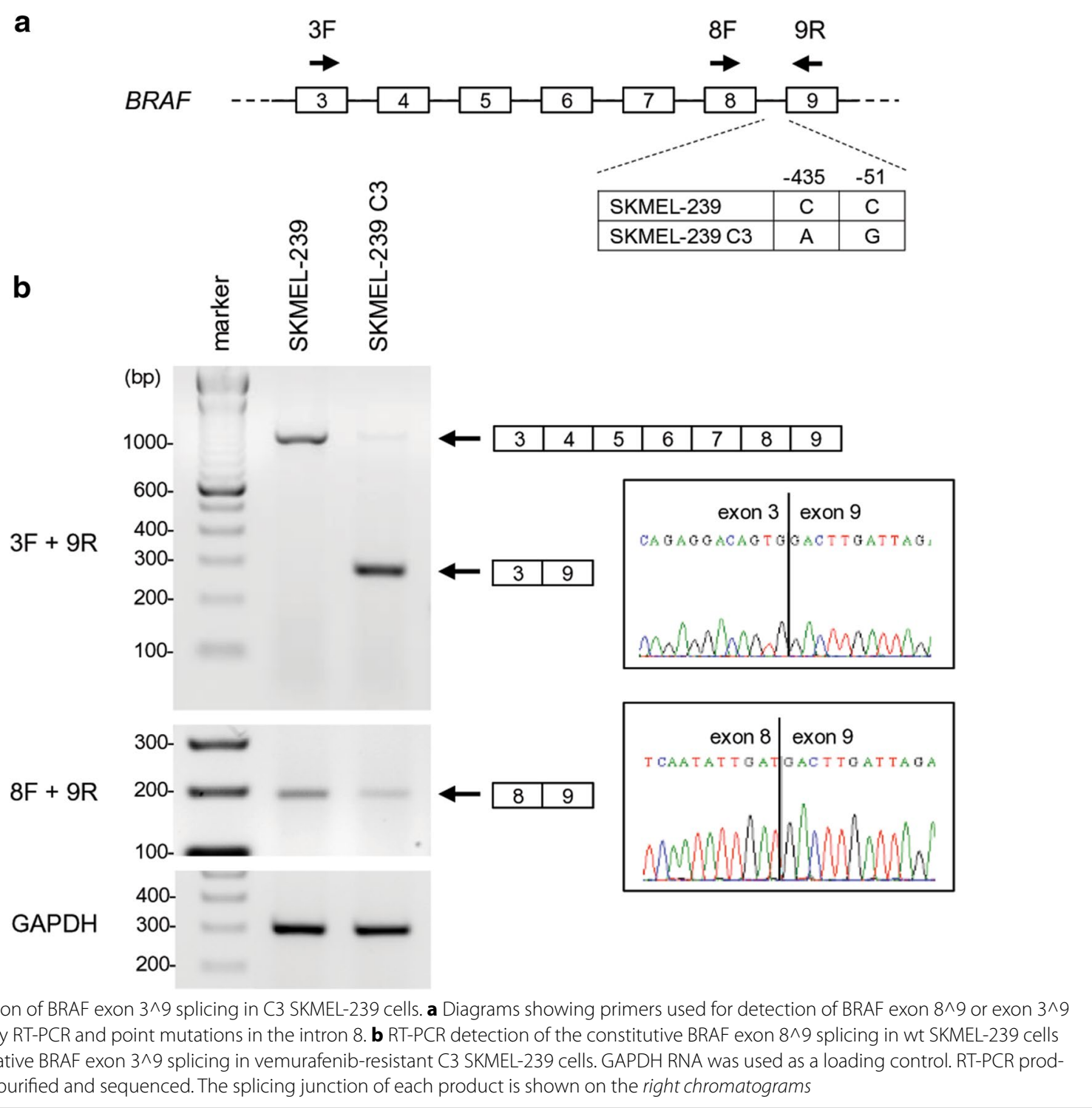

splice site were identified twice each in the branching reaction of the wt BRAF RNA splicing (Fig. 4c, d). We also identified a single bacterial colony containing a $-15 \mathrm{~A}$ or $-25 \mathrm{~A}$ in wt lariats. For the mt lariat RT-PCR products, we identified 15 colonies with the insertion, of which the $-22 \mathrm{~A},-18 \mathrm{~A}$ and $-15 \mathrm{~A}$ were identified from multiple colonies for in branching reaction of mt BRAF RNA splicing (Fig. 4c, d) and the -20A and -26A were found each only in a single colony. Surprisingly, none of the screened colonies showed a BP at the $-51 \mathrm{C}(\mathrm{wt})$ or $-51 \mathrm{G}(\mathrm{mt})$, nor a cryptic BP at the $-88 \mathrm{U}$ or $-109 \mathrm{U}$ [11] as predicted by ESEfinder [34]. The C-to-G mutation at -51 was also found not to alter the conservation value of the predicted 7-nt BPS (Fig. 1b).
In summary, our data demonstrate that wt and $\mathrm{mt}$ BRAF RNA select a distinct set of alternative BPs in the intron 8 for splicing, with the wt BRAF using distal BPs $(-29 \mathrm{~A},-28 \mathrm{~A}$ and $-26 \mathrm{~A})$ to the intron $3^{\prime}$ splice site for the exon $8^{\wedge} 9$ splicing and the $\mathrm{mt}$ BRAF using proximal BPs $(-22 \mathrm{~A},-18 \mathrm{~A}$ and $-15 \mathrm{~A})$ to the intron $3^{\prime}$ splice site for the exon $3^{\wedge} 9$ splicing (Fig. $4 \mathrm{e}$ ).

Flexibility or redundancy in BP selection has a role in alternative splicing and was described in both viral [33, 35-37] and human gene expression [27, 38]. Recent genome-wide BP mapping studies indicate that a large proportion of introns have more than one BP, generally clustered in close proximity in relation to the $3^{\prime}$ splice site $[27,38]$, although a BP could be found in rare case further 


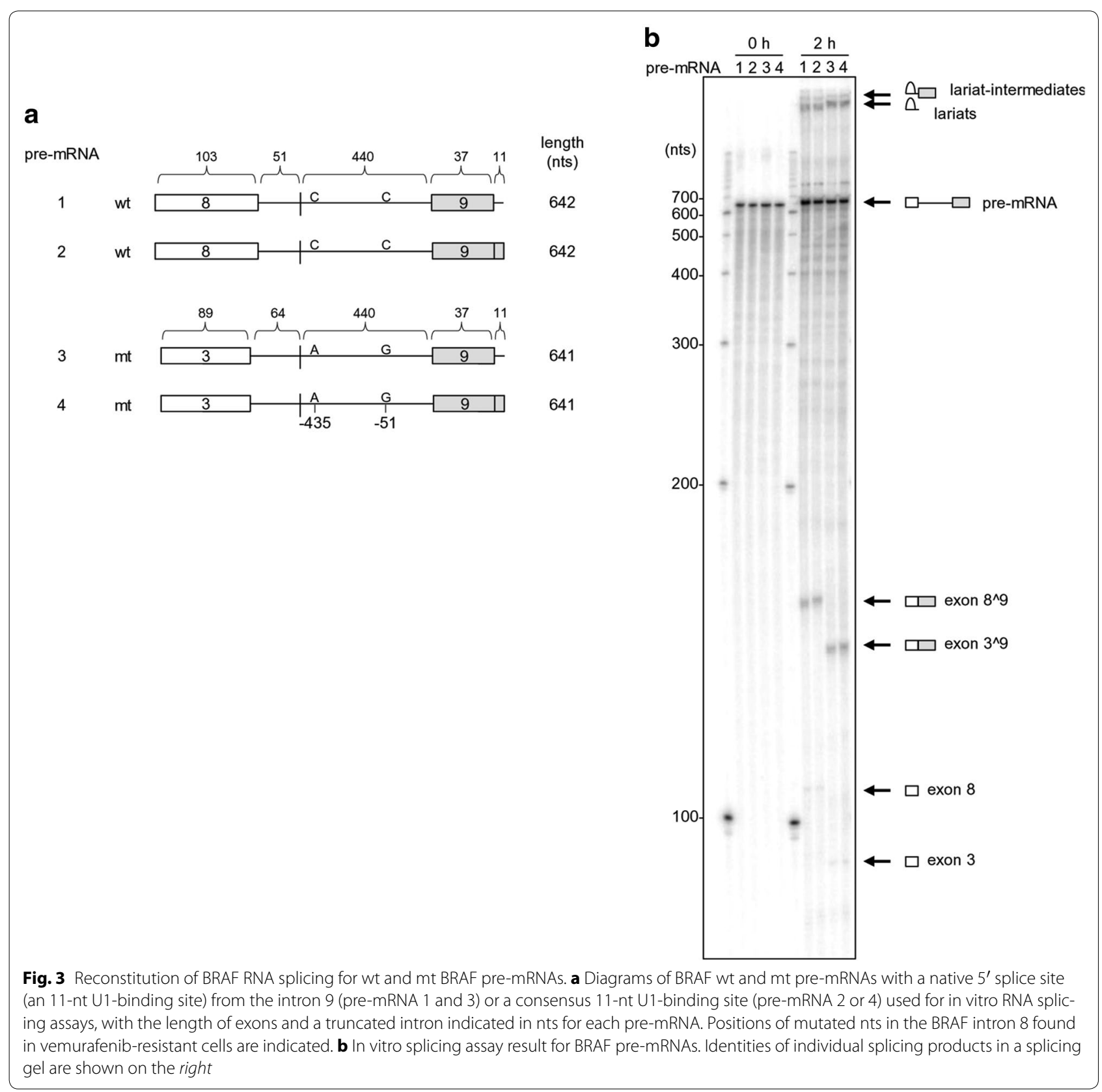

upstream of a $3^{\prime}$ splice site $[27,38]$. Since the predicted $-51 C$ [11] from the $3^{\prime}$ splice site of intron 8 identified by ESEfinder [34] or by Human Splice Finder [28] was not mapped as an authentic BP in this study, our data imply that the observed mutations (-435 C-to- $\mathrm{A}$ and $-51 \mathrm{C}$-toG) in the mt BRAF pre-mRNA might disrupt the binding of trans-acting factors, such as SRSF6 (SRp55) [11, 39, $40]$ and SF3b/3a [41-45], to the -51 region and thereby prevent the recruitment of SF1 and U2 snRNA [46-48] to select an authentic distal BP for splicing of BRAF RNA. Consequently, loss of splicing factor binding to the -51 region and activation of a proximal $\mathrm{BP}$ usage might lead to skipping of exons $4-8$ in splicing of mt BRAF. The minigene system in this report constructed in a classical way [49-52] has some advantage over the minigene in other study [11]. The latter had an extremely large $(>1 \mathrm{~kb})$ middle exon (an exon 4/8 fusion exon inserted with a strawberry reporter) and a BRAF exon 9 as a terminal exon fused with a GFP reporter [11]. An oversized internal exon larger than 500 nts has been shown to affect exon definition and thereby RNA splicing [16]. In summary, our observation provides further insight into the 


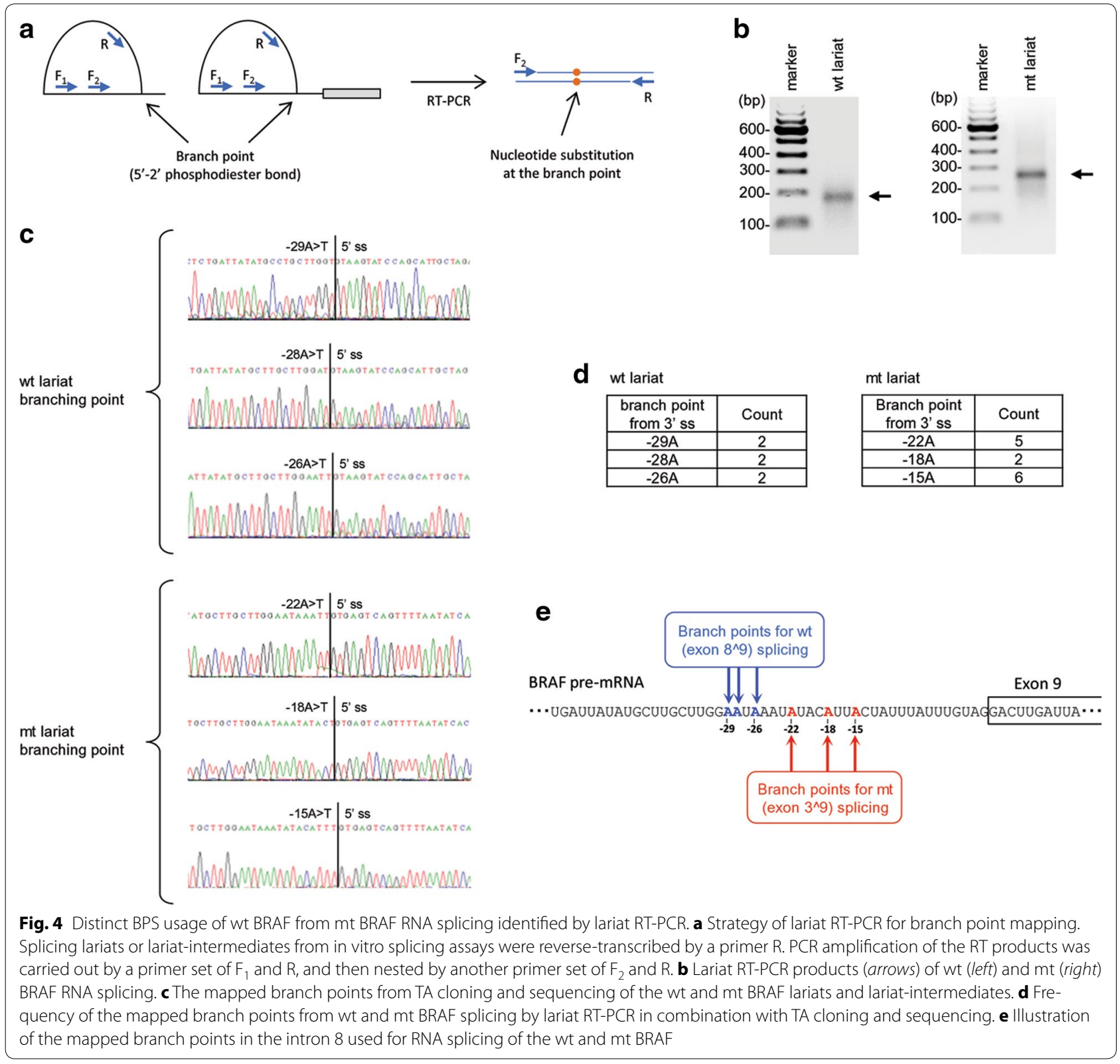

molecular mechanisms toward understanding the regulation of alternative splicing of BRAF upon vemurafenib resistance in melanoma.

\section{Methods}

\section{RT-PCR, in vitro splicing assay and lariat RT-PCR}

RT-PCR is performed as described [36] for wt SKMEL239 cells and C3 SKMEL-239 melanoma cells. Two primer sets were used separately with the primer pair of $3 \mathrm{~F}$ and $9 \mathrm{R}$ for detection of both the constitutive and alternative BRAF RNA splicing and $8 \mathrm{~F}$ and $9 \mathrm{R}$ only for the constitutive exon $8^{\wedge} 9$ splicing (Additional file 1: Table
S1; Fig. 2a). GAPDH RNA was detected with a primer pair described [36] as a loading control.

BRAF pre-mRNAs were prepared by in vitro transcription with T7 RNA polymerase from two-exon, one-intron DNA templates prepared by overlapping PCR [31, 36]. The wt BRAF template has a truncated intron 8 originally from SKMEL-239 cells and the mt BRAF template from C3 SKMEL-239 cells has a chimeric intron 3 and intron 8 of which the intron $35^{\prime}$ splice site (64 nts) was fused with the intron $83^{\prime}$ splice site (440 nts) including the point mutations in the intron (Fig. 3a). See primer details for template preparation in Additional file 1: Table S1. 
In vitro splicing assay was performed as described $[29,36,53]$. Briefly, 4 ng of ${ }^{32} \mathrm{P}$-labeled pre-mRNAs were incubated with HeLa cell nuclear extract at $30{ }^{\circ} \mathrm{C}$ for a $2 \mathrm{~h}$ in vitro splicing reaction and followed by extraction of splicing products. The splicing products were resolved by electrophoresis on a $6 \%$ denaturing PAGE gel. Autoradiograph was captured by PhosphorImager Storm 860 (GE Healthcare Life Sciences, Pittsburgh, PA).

For lariat RT-PCR [31-33], in vitro splicing products from $100 \mathrm{ng}$ of cold pre-mRNAs were reverse transcribed by Superscript II (Life technologies, Thermo Fisher Scientific) using a primer $\mathrm{R}$ and amplified by PCR with a primer pair of R and F1 first followed by a nested primer pair of R and F2 (Fig. 4a; Additional file 1: Table S1). The lariat RT-PCR products were subcloned into the pCR2.1 TOPO vector (Life Technologies) and sequenced.

\section{Additional file}

Additional file 1: Table S1. BRAF primers used in this study.

\section{Authors' contributions}

MA participated in the design of the study, performed all experiments and analysis of the data. ZMZ designed the study and analyzed the data. MA and ZMZ drafted. Both authors read and approved the final manuscript.

\section{Acknowledgements}

We thank Tom Misteli and Maayan Salton for providing us the cellular materials of wt SKMEL-239 cells and C3 SKMEL-239 melanoma cell lines and critical reading of the manuscript.

\section{Competing interests}

Both authors declare that they have no competing interests.

\section{Funding}

This research was supported by the Intramural Research Program of the NIH, National Cancer Institute, Center for Cancer Research.

Received: 4 November 2015 Accepted: 14 December 2015 Published online: 21 December 2015

\section{References}

1. Davies H, Bignell GR, Cox C, Stephens P, Edkins S, Clegg S, Teague J, Woffendin $\mathrm{H}$, Garnett MJ, Bottomley W, et al. Mutations of the BRAF gene in human cancer. Nature. 2002;417:949-54.

2. Curtin JA, Fridlyand J, Kageshita T, Patel HN, Busam KJ, Kutzner H, Cho KH, Aiba S, Brocker EB, LeBoit PE, et al. Distinct sets of genetic alterations in melanoma. N Engl J Med. 2005;353:2135-47.

3. McArthur GA, Chapman PB, Robert C, Larkin J, Haanen JB, Dummer R, Ribas A, Hogg D, Hamid O, Ascierto PA, et al. Safety and efficacy of vemurafenib in BRAF(V600E) and BRAF(V600K) mutation-positive melanoma (BRIM-3): extended follow-up of a phase 3, randomised, open-label study. Lancet Oncol. 2014;15:323-32.

4. Chapman PB, Hauschild A, Robert C, Haanen JB, Ascierto P, Larkin J, Dummer R, Garbe C, Testori A, Maio M, et al. Improved survival with vemurafenib in melanoma with BRAF V600E mutation. N Engl J Med. 2011;364:2507-16.
5. Flaherty KT, Puzanov I, Kim KB, Ribas A, McArthur GA, Sosman JA, O'Dwyer PJ, Lee RJ, Grippo JF, Nolop K, et al. Inhibition of mutated, activated BRAF in metastatic melanoma. N Engl J Med. 2010;363:809-19.

6. Johannessen CM, Boehm JS, Kim SY, Thomas SR, Wardwell L, Johnson LA, Emery CM, Stransky N, Cogdill AP, Barretina J, et al. COT drives resistance to RAF inhibition through MAP kinase pathway reactivation. Nature. 2010:468:968-72.

7. Montagut C, Sharma SV, Shioda T, McDermott U, Ulman M, Ulkus LE, DiasSantagata D, Stubbs H, Lee DY, Singh A, et al. Elevated CRAF as a potential mechanism of acquired resistance to BRAF inhibition in melanoma. Cancer Res. 2008:68:4853-61.

8. Villanueva J, Vultur A, Lee JT, Somasundaram R, Fukunaga-Kalabis M, Cipolla AK, Wubbenhorst B, Xu X, Gimotty PA, Kee D, et al. Acquired resistance to BRAF inhibitors mediated by a RAF kinase switch in melanoma can be overcome by cotargeting MEK and IGF-1R/PI3K. Cancer Cell. 2010;18:683-95.

9. Sun C, Wang L, Huang S, Heynen GJ, Prahallad A, Robert C, Haanen J, Blank C, Wesseling J, Willems SM, et al. Reversible and adaptive resistance to BRAF(V600E) inhibition in melanoma. Nature. 2014;508:118-22.

10. Poulikakos PI, Persaud Y, Janakiraman M, Kong X, Ng C, Moriceau G, Shi $H$, Atefi M, Titz B, Gabay MT, et al. RAF inhibitor resistance is mediated by dimerization of aberrantly spliced BRAF(V600E). Nature. 2011:480:387-90.

11. Salton M, Kasprzak WK, Voss T, Shapiro BA, Poulikakos PI, Misteli T. Inhibition of vemurafenib-resistant melanoma by interference with pre-mRNA splicing. Nat Commun. 2015;6:7103.

12. Graveley BR. Sorting out the complexity of SR protein functions. RNA. 2000;6:1197-211.

13. Zheng ZM. Regulation of alternative RNA splicing by exon definition and exon sequences in viral and Mammalian gene expression. J Biomed Sci. 2004; 11:278-94.

14. Fu XD, Ares M Jr. Context-dependent control of alternative splicing by RNA-binding proteins. Nat Rev Genet. 2014;15:689-701.

15. Berget SM. Exon recognition in vertebrate splicing. J Biol Chem. 1995;270:2411-4.

16. Sterner DA, Carlo T, Berget SM. Architectural limits on split genes. Proc Natl Acad Sci USA. 1996;93:15081-5.

17. Hamm J, Mattaj IW. Monomethylated cap structures facilitate RNA export from the nucleus. Cell. 1990;63:109-18.

18. Sun H, Chasin LA. Multiple splicing defects in an intronic false exon. Mol Cell Biol. 2000;20:6414-25.

19. Dou Y, Fox-Walsh KL, Baldi PF, Hertel KJ. Genomic splice-site analysis reveals frequent alternative splicing close to the dominant splice site. RNA. 2006;12:2047-56.

20. Kondo Y, Oubridge C, van Roon AM, Nagai K. Crystal structure of human U1 snRNP, a small nuclear ribonucleoprotein particle, reveals the mechanism of 5' splice site recognition. Elife. 2015;4:e04986.

21. Rossi F, Forne T, Antoine E, Tazi J, Brunel C, Cathala G. Involvement of U1 small nuclear ribonucleoproteins (snRNP) in $5^{\prime}$ splice site-U1 snRNP interaction. J Biol Chem. 1996;271:23985-91.

22. Malca H, Shomron N, Ast G. The U1 snRNP base pairs with the $5^{\prime}$ splice site within a penta-snRNP complex. Mol Cell Biol. 2003;23:3442-55.

23. Green MR. Pre-mRNA splicing. Annu Rev Genet. 1986;20:671-708.

24. Zhuang YA, Goldstein AM, Weiner AM. UACUAAC is the preferred branch site for mammalian mRNA splicing. Proc Natl Acad Sci USA. 1989;86:2752-6.

25. Gao K, Masuda A, Matsuura T, Ohno K. Human branch point consensus sequence is yUnAy. Nucleic Acids Res. 2008;36:2257-67.

26. Corvelo A, Hallegger M, Smith CW, Eyras E. Genome-wide association between branch point properties and alternative splicing. PLoS Comput Biol. 2010;6:e1001016

27. Mercer TR, Clark MB, Andersen SB, Brunck ME, Haerty W, Crawford J, Taft RJ, Nielsen LK, Dinger ME, Mattick JS. Genome-wide discovery of human splicing branchpoints. Genome Res. 2015;25:290-303.

28. Desmet FO, Hamroun D, Lalande M, Collod-Beroud G, Claustres M Beroud C. Human splicing finder: an online bioinformatics tool to predict splicing signals. Nucleic Acids Res. 2009;37:e67.

29. Zheng ZM, Tao M, Yamanegi K, Bodaghi S, Xiao W. Splicing of a Capproximal human papillomavirus 16 E6E7 intron promotes E7 expression, but can be restrained by distance of the intron from its RNA $5^{\prime}$ Cap. J Mol Biol. 2004;337:1091-108. 
30. Zheng ZM, He P, Baker CC. Selection of the bovine papillomavirus type 1 nucleotide $32253^{\prime}$ splice site is regulated through an exonic splicing enhancer and its juxtaposed exonic splicing suppressor. J Virol. 1996;70:4691-9.

31. Zheng ZM, Reid ES, Baker CC. Utilization of the bovine papillomavirus type 1 late-stage-specific nucleotide $36053^{\prime}$ splice site is modulated by a novel exonic bipartite regulator but not by an intronic purine-rich element. J Virol. 2000;74:10612-22.

32. Vogel J, Hess WR, Borner T. Precise branch point mapping and quantification of splicing intermediates. Nucleic Acids Res. 1997;25:2030-1.

33. Ajiro $M$, Zheng $Z M$. E6^E7, a novel splice isoform protein of human papillomavirus 16, stabilizes viral E6 and E7 oncoproteins via HSP90 and GRP78. MBio. 2015;6:e02068.

34. Cartegni L, Wang J, Zhu Z, Zhang MQ, Krainer AR. ESEfinder: a web resource to identify exonic splicing enhancers. Nucleic Acids Res. 2003;31:3568-71.

35. Zheng ZM, Quintero J, Reid ES, Gocke C, Baker CC. Optimization of a weak $3^{\prime}$ splice site counteracts the function of a bovine papillomavirus type 1 exonic splicing suppressor in vitro and in vivo. J Virol. 2000;74:5902-10.

36. Ajiro M, Jia R, Zhang L, Liu X, Zheng ZM. Intron definition and a branch site adenosine at nt 385 control RNA splicing of HPV16 E6*I and E7 expression. PLoS One. 2012;7:e46412.

37. Majerciak V, Yamanegi K, Zheng ZM. Gene structure and expression of Kaposi's sarcoma-associated herpesvirus ORF56, ORF57, ORF58, and ORF59. J Virol. 2006;80:11968-81

38. Taggart AJ, DeSimone AM, Shih JS, Filloux ME, Fairbrother WG. Largescale mapping of branchpoints in human pre-mRNA transcripts in vivo. Nat Struct Mol Biol. 2012;19:719-21.

39. Tran Q, Roesser JR. SRp55 is a regulator of calcitonin/CGRP alternative RNA splicing. Biochemistry. 2003;42:951-7.

40. Mercado PA, Ayala YM, Romano M, Buratti E, Baralle FE. Depletion of TDP 43 overrides the need for exonic and intronic splicing enhancers in the human apoA-II gene. Nucleic Acids Res. 2005;33:6000-10.

41. Gozani O, Potashkin J, Reed R. A potential role for U2AF-SAP 155 interactions in recruiting U2 snRNP to the branch site. Mol Cell Biol. 1998;18:4752-60.
42. Lardelli RM, Thompson JX, Yates JR III, Stevens SW. Release of SF3 from the intron branchpoint activates the first step of pre-mRNA splicing. RNA. 2010;16:516-28

43. Kfir N, Lev-Maor G, Glaich O, Alajem A, Datta A, Sze SK, Meshorer E, Ast G. SF3B1 association with chromatin determines splicing outcomes. Cell Rep. 2015;11:618-29.

44. Brosi R, Hauri HP, Kramer A. Separation of splicing factor SF3 into two components and purification of SF3a activity. J Biol Chem. 1993;268:17640-6.

45. Corrionero A, Minana B, Valcarcel J. Reduced fidelity of branch point recognition and alternative splicing induced by the anti-tumor drug spliceostatin A. Genes Dev. 2011;25:445-59.

46. Kramer A. Purification of splicing factor SF1, a heat-stable protein that functions in the assembly of a presplicing complex. Mol Cell Biol. 1992;12:4545-52.

47. Berglund JA, Abovich N, Rosbash M. A cooperative interaction between U2AF65 and mBBP/SF1 facilitates branchpoint region recognition. Genes Dev. 1998;12:858-67.

48. Crisci A, Raleff F, Bagdiul I, Raabe M, Urlaub H, Rain JC, Kramer A. Mammalian splicing factor SF1 interacts with SURP domains of U2 snRNPassociated proteins. Nucleic Acids Res. 2015. doi:10.1093/nar/gkv952.

49. Reed R, Maniatis T. The role of the mammalian branchpoint sequence in pre-mRNA splicing. Genes Dev. 1988;2:1268-76.

50. Ibrahim EC, Schaal TD, Hertel KJ, Reed R, Maniatis T. Serine/arginine-rich protein-dependent suppression of exon skipping by exonic splicing enhancers. Proc Natl Acad Sci USA. 2005;102:5002-7.

51. Zheng ZM, Huynen M, Baker CC. A pyrimidine-rich exonic splicing suppressor binds multiple RNA splicing factors and inhibits spliceosome assembly. Proc Natl Acad Sci USA. 1998;95:14088-93.

52. Noble JC, Pan ZQ, Prives C, Manley JL. Splicing of SV40 early pre-mRNA to large $T$ and small t mRNAs utilizes different patterns of lariat branch sites. Cell. 1987;50:227-36.

53. Zheng ZM, Baker CC. Parameters that affect in vitro splicing of bovine papillomavirus type 1 late pre-mRNAs. J Virol Methods. 2000;85:203-14.

\section{Submit your next manuscript to BioMed Central and we will help you at every step:}

- We accept pre-submission inquiries

- Our selector tool helps you to find the most relevant journal

- We provide round the clock customer support

- Convenient online submission

- Thorough peer review

- Inclusion in PubMed and all major indexing services

- Maximum visibility for your research

Submit your manuscript at www.biomedcentral.com/submit
() Biomed Central 